\title{
Screening Method for Rapid Determination of Polychlorinated Biphenyls in Transformer Oil by Liquid-Liquid Extraction and Gas Chromatography-Mass Spectrometry
}

\author{
Carla Toledo, Luis Valle, Jessica Narváez and Pablo Richter* \\ Departamento de Química Inorgánica y Analítica, Centro de Estudios para el Desarrollo de la Química \\ (CEPEDEQ), Facultad de Ciencias Químicas y Farmacéuticas, Universidad de Chile, \\ Casilla 233, Santiago, Chile
}

\begin{abstract}
Um método simples e rápido foi desenvolvido para análise de bifenis policlorados (PBC) em transformadores a óleo. O método baseia-se na extração líquido-líquido em metanol e subseqüente determinação direta por cromatografia gasosa acoplada a espectrômetro de massa. A polaridade do metanol permite extrair PCBs, junto com uma quantidade mínima de componentes apolares do óleo, evitando assim etapas demoradas na preparação de amostras. Uma vez que o padrão estabelecido internacionalmente para resíduos contento PCBs é $50 \mathrm{mg}$ $\mathrm{kg}^{-1}$, o método determina rapidamente se o transformador a óleo está contaminado com PCBs ou não. Para conseguir as melhores condições de extração, foi realizada uma otimização multivariada, considerando duas variáveis significativas: volume de metanol e tempo de extração. Sob condições ótimas, as recuperações de Aroclor 1256 e Aroclor 1260 estavam entre 80 e $100 \%$, e a precisão, expressa como desvio padrão relativo, entre 2 e $4 \%$. O método foi aplicado em amostras reais poluídas com PCBs.
\end{abstract}

A rapid and simple method was developed for screening polychlorinated biphenyls in transformer oil. The method is based on liquid-liquid extraction in methanol and subsequent direct gas chromatography-mass spectrometric determination. The extent of methanol polarity allows to extract the PCBs, co-extracting a minimum amount of the apolar oil components, thus avoiding the time-consuming steps involving in sample preparation. Since the regulation established internationally for wastes containing PCBs is $50 \mathrm{mg} \mathrm{kg}^{-1}$, the method rapidly determines whether the transformer oil is PCBs-contaminated or not. In order to reach the best conditions for extraction a multivariate optimization was carried out considering two significant variables: volume of methanol and extraction time. Under optimum conditions, recoveries of Aroclor 1256 and Aroclor 1260 were between 80 and 100\%, and precision, expressed as relative standard deviation, was from 2 to $4 \%$. The method was applied to real samples polluted with PCBs.

Keywords: PCBs, oil transformer, liquid-liquid extraction, GC-MS

\section{Introduction}

The polychlorinated biphenyls (PCBs) are 209 isomers which are synthesized through chlorination of the biphenyl rings. PCB mixtures have been used for a variety of applications, including dielectric fluids for capacitors and transformers, heat transfer fluids, hydraulic fluids, lubricating and cutting oils. PCBs are very stable compounds and do not degrade easily. Their chemical and physical stability has also been responsible for their continued steady (low-level) persistence in the environment. Due to these features, PCBs

*e-mail: prichter@ciq.uchile.cl belong to the dirty-dozen class of persistent organic pollutants (POPs).

Various analytical methods have been reported for the determination of PCBs in transformer oils. ${ }^{1-10}$ In the SW-486 series of US-EPA there are two screening methods, $4020^{1}$ and $9079 .^{2}$ In the first case PCBs concentrations may be rapidly estimated in samples of soil and non-aqueous liquid wastes. On the other hand, method 9079 corresponds to specific screening in oil transformer samples. However, for exact determination, US-EPA indicates that method $8082^{3}$ should be used through gas chromatography.

All the proposed methodologies that make use of gas chromatography involve a series of sample preparation and 
clean-up steps prior to instrumental determination since matrix components impair signal sensitivity and increase background. Clean up processes are particularly difficult because mineral oil components and PCBs have similar physical and chemical characteristics. Consequently, these methodologies may be subject to greater errors in PCBs determination and to a concomitant excessive expenditure on reagents. The reported chromatographic methods are mainly coupled to the following detectors: atomic emission detector (AED), ${ }^{4}$ electron capture detector (ECD) ${ }^{5-7}$ and mass selective detector, ${ }^{8,9}$ including high resolution mass spectrometry. ${ }^{10}$

At the moment is indubitable the necessity to develop screening methods which can provide rapid analytical information. The conventional analytical methods usually are time-consuming because they are designed to provide detailed qualitative and quantitative information about the analytes in the sample, which normally is not mandatory for rapid decisions. In this context, the development of more rapid and efficient methodologies for the sample pretreatment is an important trend in analytical chemistry.

In this context, in the present study a rapid method was developed and validated, based on liquid-liquid extraction using methanol as a solvent and on direct analyte determination in the extract by mass spectrometry, utilizing selective ion monitoring (SIM) to determine different Aroclors (Aroclor 1242, 1254, and $1260)$ in transformer oil. The amount of co-extracted oil is small and it only interferes with the exact determination of di-, tri-, and tretrachlorinated congeners. In this context, direct extraction with methanol followed by injection into a GC-MS permits to determine rapidly whether or not oil is contaminated above the $50 \mathrm{mg} \mathrm{kg}^{-1}$ regulatory level (Basel Convention, 2003). For accurate determination of all the interfered congeners, it is necessary to clean up the extract with concentrated sulphuric acid. For better recovery of the extracted PCBs it was necessary to optimize both extracting solvent volume and extraction time. This optimization was done through an experimental design. Finally, the method was applied to real samples of transformer oils.

\section{Experimental}

\section{Reagents}

Standards of Aroclors 1242, 1254, and 1260 (1000 $\mu \mathrm{g} \mathrm{mL}^{-1}$ ) (Supelco, Bellefonte, PA, USA) were utilized to calibrate and for PCBs recovery studies. A standard PCB mixture-525.1 (100 $\left.\mu \mathrm{g} \mathrm{mL}^{-1}\right)$ (Chem Service, West Chester. PA, USA) was utilized in methanol (GC-MS/
Pesticide grade analysis, Fisher Scientific, Fair Lawn NJ, USA) to optimize the variables. Transformer oil free of PCBs (Supelco, Bellefonte, PA, USA) was spiked with the above mentioned standards at different concentration levels for optimization and recovery studies. As internal standard $15 \mu \mathrm{g} \mathrm{mL}^{-1}$ hexachlorobenzene (Supelco, Bellefonte, PA, USA) was used.

For exact determination of di-, tri-, and tetrachlorinated congeners, clean-up was carried out using $n$-hexane (GCMS/ Pesticide grade analysis, Fisher Scientific, Fair Lawn New Jersey, USA) and 95-97\% sulphuric acid (Merck, Darmstadt, Germany). 5.0 UHP helium (AGA, Chile) was used as a carrier gas in GC-MS.

\section{Instruments and apparatus}

A Heildolph Reax 2000 vortex stirrer was used to extract the analytes from the oil samples. The methanol/ oil phases were separated with a Labofurge 400 Haraeus Instruments centrifuge. An HP 5890 Series II gas chromatograph coupled to a Fisons quadrupolar mass spectrometer was utilized for PCBs quantitation.

\section{Extraction procedure}

Portions of about $3.5 \mathrm{~g}$ of transformer oil were accurately weighed in a glass centrifuge tube, and 6 $\mathrm{mL}$ methanol was added as a PCBs-extracting solvent. The sample was stirred for one minute in a vortex stirrer. Once the extracting process was finished, the sample was centrifuged in order to separate the phases. First, $4 \mathrm{~mL}$ of the methanol phase was placed in a glass tube with a ground-glass stopper. Then, $40 \mu \mathrm{L}$ of $1000 \mu \mathrm{g}$ $\mathrm{mL}^{-1}$ hexachlorobenzene was added to be used as an internal standard. Finally, $1 \mu \mathrm{L}$ of the sample was injected into a GC-MS to determine the PCBs. The concentration of PCBs in real samples was calculated using the calibration curve and the results were expressed as the corresponding Aroclor found in the sample.

\section{Clean-up process}

In order to obtain an accurate determination of lowmolecular-weight PCBs from dichlorobiphenyls through tetrachlorobyphenyls, the following clean-up process was carried out: $4 \mathrm{~mL}$ methanol extract was diluted with $n$-hexane to reach $20 \mathrm{~mL}$; then, portions of $10 \mathrm{~mL}$ concentrated $\mathrm{H}_{2} \mathrm{SO}_{4}$ were sequentially added to clean up the sample until the colourless sulphuric acid phase was obtained. ${ }^{11}$ Finally, the $n$-hexane phase was evaporated 
down to $2 \mathrm{~mL}$, internal standard was added, and a volume of $1 \mu \mathrm{L}$ was injected into the GC-MS.

\section{GC-MS conditions}

Final determination was carried out by GC-MS using a HP-5MS fused silica capillary column $(30 \mathrm{~m} \times 0.25$ $\mathrm{mm}$ i.d., and $0.25 \mu \mathrm{m}$ film thickness) coated with $5 \%$ phenyl-95\% methylpolysiloxane. One microliter of extract was injected into the column using splitless mode. Injector temperature was $250{ }^{\circ} \mathrm{C}$. Column temperature was maintained at $50{ }^{\circ} \mathrm{C}$ for $3 \mathrm{~min}$, raised up to $280{ }^{\circ} \mathrm{C}$ at

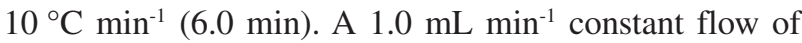
helium as carrier gas as set.

The MS transfer line was held at $280^{\circ} \mathrm{C}$ and quantitations were based on calibration with standard analytes using the mass spectrometric parameters (SIM mode) shown in Table 1. The ions mentioned for each analyte in Table 1 were used for quantitation (target ion) and confirmation (qualifier ions). The relative abundance ion ratio should match the comparison standard within $\pm 20 \%$.

\section{Experimental designs}

A screening-type experimental design (mixed level factorial plus three centrals points $3 \times 2+3=9$ experiments) was carried out to optimize PCBs extraction from transformer oils. For this study, a PCB-free oil was utilized, which was spiked with a known standard concentration (PCB mixture525.1) containing the following congeners considered as representative: 2-chlorobiphenyl; 2,3-dichlorobiphenyl; 2,4,5-trichlorobiphenyl; 2,2',4,4'-tetrachlorobiphenyl; 2,2',3',4,6-pentachlorobiphenyl; 2,2',4,4',5,6'-hexachlorobiphenyl; 2,2',3,3',4,4',6-heptachlorobiphenyl and 2,2',3,3',4,5',6,6'-octachlorobiphenyl.

\section{Recovery study}

A PCBs-free transformer oil was spiked with a known amount (10 and $60 \mathrm{mg} \mathrm{kg}^{-1}$ ) of Aroclor 1242, Aroclor 1254, and Aroclor 1260. The extraction procedure was followed, the extracts were subjected to GC-MS and the recoveries of each Aroclor at both concentration levels were calculated by reference to the calibration graphs.

\section{Results and Discussion}

The proposed method is based on liquid-liquid extraction of PCBs from transformer oil using methanol as a solvent and on direct analyte determination in the extract by mass spectrometry, utilizing selective ion monitoring (SIM) to determine different Aroclors. A small amount of oil is co-extracted as can be seen in the TIC chromatogram of a blank (PCB free-oil) extract shown in Figures 1A and 1B. The signals observed in Figure 1A interfere with the exact determination of di-, tri-, and tetra-chlorinated congeners, when their specific ions (Table 1) are monitored. If these specific ions are not monitored these signals disappears (Figure 1B). Figure $1 \mathrm{C}$ shows the TIC chromatogram of an extract of
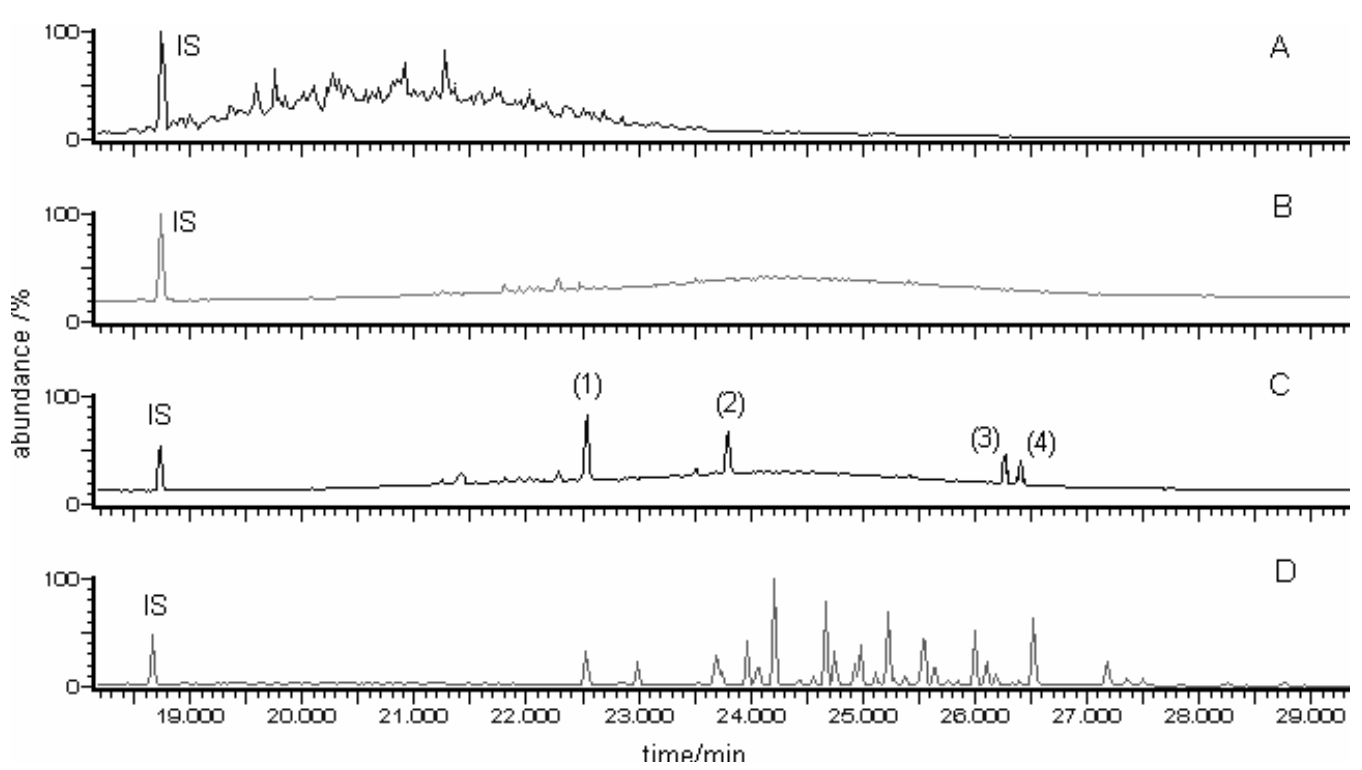

Figure 1. TIC chromatograms of different extracts. (A) Extract of PCB- free transformer oil, the monitored ions cover the interval among di- and octa- chlorobifenils. (B) Same as (A) but the monitored ions cover the interval among penta- and octa- chlorobifenils. (C) Extract of a synthetic sample constituted by PCB-free oil spiked with the standard PCB mixture-525.1, (1) 2,2',3',4,6-pentachlorobiphenyl; (2) 2,2',4,4',5,6'-hexachlorobiphenyl; (3) 2,2',3,3',4,4',6-heptachlorobiphenyl; and (4) 2,2',3,3',4,5',6,6'-octachlorobiphenyl. (D) Extract of a real sample. (IS) Internal Standard. 
a synthetic sample constituted by PCB free-oil spiked with the standard PCB mixture-525.1. In this chromatogram only the congeners penta, hexa, hepta, octa are monitored and, it can be seen the signals are well resolved and the oil extract do not interfere. Otherwise, Figure 1D shows a TIC chromatogram of a real sample containing mainly Aroclor 1260.

Table 1. Target and qualifier ions used for the SIM method

\begin{tabular}{lcccccc}
\hline Ion & \multicolumn{7}{c}{ Congener } \\
\cline { 2 - 7 } & di & tri & tetra & penta & hexa & hepta \\
\hline Target $(\mathrm{m} / z)$ & 224 & 258 & 292 & 326 & 360 & 394 \\
Qualifier $(\mathrm{m} / \mathrm{z})$ & 152 & 186 & 220 & 324 & 358 & 392 \\
& 222 & 256 & 290 & 328 & 362 & 396
\end{tabular}

\section{Optimization of extraction variables through a mixed-level design}

Extracting solvent volume and extraction time, which in addition can interact with each other, were considered the variables affecting most significantly PCBs extraction from transformer oil. Bearing these facts in mind, both variables were optimized through a $3 \times 2$ mixed-level factorial design with three centrals points randomly distributed, which accounts for possible interactions. Table 2 shows the factors and levels under study. The experimental design matrix is shown in Table 3 . It should be noted that, with the exclusion of the central points, the volume factor considers three levels, and the time factor,

Table 2. Factors and levels considered in the experimental design

\begin{tabular}{lcc}
\hline \multirow{2}{*}{ Factor } & \multicolumn{2}{c}{ Level } \\
\cline { 2 - 3 } & Low & High \\
\hline Solvent volume, $\times_{1}(\mathrm{~mL})$ & 2.0 & 10.0 \\
Extraction time, $\times_{2}(\mathrm{~min})$ & 1.0 & 10.0 \\
\hline
\end{tabular}

Table 3. Experimental matrix $(3 \times 2)$ in the experimental design

\begin{tabular}{lcccc}
\hline \multirow{2}{*}{ Run } & \multicolumn{2}{c}{ Codified variables } & \multicolumn{2}{c}{ No codified variables } \\
\cline { 2 - 5 } & $\times_{1}$ & $\times_{2}$ & $\times_{1}$ & $\times_{2}$ \\
\hline 1 & 0 & 0 & 6 & 5.5 \\
2 & -1 & -1 & 2 & 1 \\
3 & -1 & 1 & 2 & 10 \\
4 & 0 & -1 & 6 & 1 \\
5 & 0 & 0 & 6 & 5.5 \\
6 & 0 & 1 & 6 & 10 \\
7 & 1 & -1 & 10 & 1 \\
8 & 1 & 1 & 10 & 10 \\
9 & 0 & 0 & 6 & 5.5
\end{tabular}

$\mathrm{x}_{1}$ : Solvent volume $(\mathrm{mL}) ; \mathrm{x}_{2}$ : Extraction time $(\mathrm{min})$. two levels. The response considers the relationship between the sum of the chromatographic areas of selected analytes (2,2',3',4,6-pentachlorobiphenyl; 2,2', 4,4',5,6'hexachlorobiphenyl; 2,2',3,3',4,4',6-heptachlorobiphenyl; and $2,2^{\prime}, 3,3^{\prime}, 4,5^{\prime}, 6,6^{\prime}$-octachlorobiphenyl) and the internal standard area (Figure 1C). In this design ANOVA assessed the statistical significance of the factors at a probability level of $95 \%(\alpha=0.05)$.

The design indicates that the model fits adequately to experimental data, since it showed a correlation coefficient (R) of $95.93 \%$, a standard error of 0.008 , and a standard error corresponding to residues of 0.017 . The response surface in Figure 2 is accounted for by a linear secondorder model:

Response $=0.0540+0.0797 \times \mathrm{V}-0.0066 \times \mathrm{T}-0.0063 \times \mathrm{V}^{2}$ $+0.0002 \times \mathrm{V} \times \mathrm{T}$

where $\mathrm{V}$ represents the volume variable and $\mathrm{T}$ represents the time variable.

Figure 2 shows the response surface of the optimization of both variables. It may be observed that both in the second-order equation and in Figure 2 the more important factor is the volume of utilized solvent, since it shows a response variation much greater than the one observed for extraction time, which practically shows no variation. The same is observed in Pareto chart (Figure 3), clearly indicating that the most significant variables are extraction

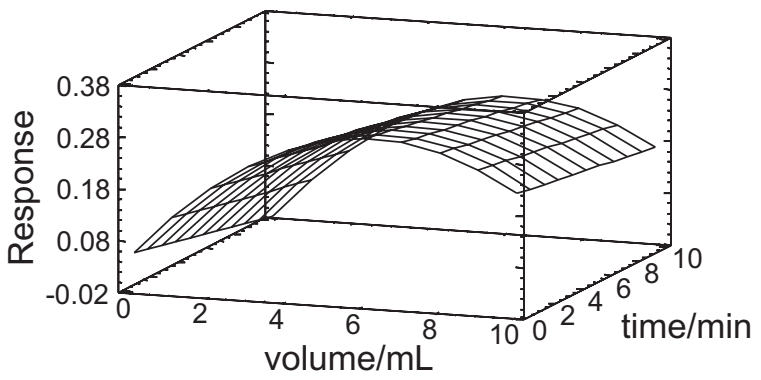

Figure 2. Estimated response surface.

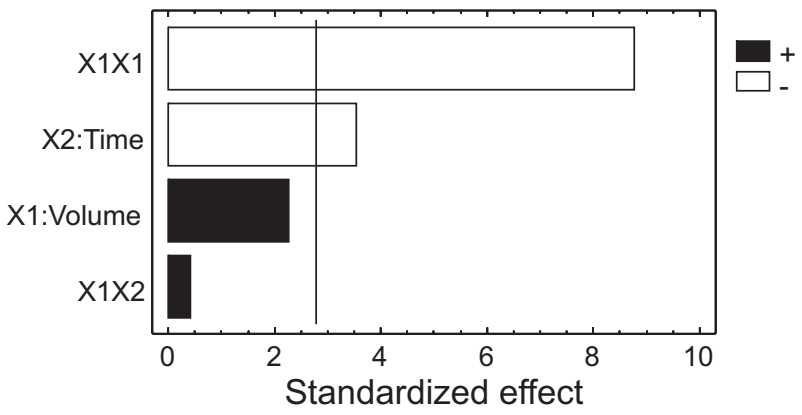

Figure 3. Standardized Pareto chart. 
time $\left(\mathrm{X}_{2}\right)$ and the interaction (quadratic effect) of methanol volume $\left(\mathrm{X}_{1} \mathrm{X}_{1}\right)$, since it goes beyond the vertical line representing $95 \%$ significance ( $\mathrm{p}$-value $<0.05$ ). This volume-volume interaction $\left(\mathrm{X}_{1} \mathrm{X}_{1}\right)$ may be accounted for by the dual effect of the factor. This means that that the respective effect of the volume is nonlinear. On the other hand, the increase in extraction time brings about a decrease in the response, mainly due to increasing coextraction of other oil components with increasing time. Optimum variable values predicted by the experimental design may be seen in Table 4 .

Table 4. Optimum values found for each studied factor

\begin{tabular}{lc}
\hline Factor & Optimum \\
\hline Solvent volume, $\times_{1}(\mathrm{~mL})$ & 6.3 \\
Extraction time, $\times_{2}(\mathrm{~min})$ & 1 \\
\hline
\end{tabular}

\section{Analytical features and application of the method}

Calibration curves $(n=10)$ were built from the 1000 $\mathrm{mg} \mathrm{kg}^{-1}$ standards of Aroclor 1242, 1254, and 1260 at the concentration interval 10 to $100 \mathrm{mg} \mathrm{kg}^{-1}$. Table 5 shows the analytical features of the method. It is observed that regression coefficients are from 0.9990 to 0.9993 for the three Aroclors under study. Repeatability, expressed as RSD, was in all cases less than $4.4 \%$ injecting 6 extracts of the same sample. Limit of detection was less than 1 $\mathrm{mg} \mathrm{kg}^{-1}$ and was calculated applying the $3 \sigma$ criterion. $^{12}$

Recoveries of each Aroclor with the proposed method are shown in Table 6. Results show that extraction of

Table 5. Analytical features of the method

\begin{tabular}{lccccccc}
\hline Aroclor & $\mathrm{a}$ & $\mathrm{S}_{\mathrm{a}}$ & $\mathrm{b}$ & $\mathrm{S}_{\mathrm{b}}$ & $\mathrm{R}$ & $\begin{array}{c}\mathrm{LOD} / \\
\left(\mathrm{mg} \mathrm{kg}^{-1}\right)\end{array}$ & $\begin{array}{c}\mathrm{RSD} / \\
(\%)\end{array}$ \\
\hline 1242 & 0.013 & 0.008 & 0.215 & 0.003 & 0.9990 & 0.54 & 4.36 \\
1254 & 0.020 & 0.008 & 0.171 & 0.003 & 0.9993 & 0.59 & 2.25 \\
1260 & 0.013 & 0.011 & 0.215 & 0.004 & 0.9992 & 0.88 & 2.14 \\
\hline
\end{tabular}

a: intercept of the regression line; $b$ : slope of the regression line; $\mathrm{S}_{\mathrm{a}}$ : standard deviation of the intercept; $S_{b}$ : standard deviation of the slope. $R$ : correlation coefficient; LOD: limit of detection; RSD: relative standard deviation $(n=6)$.

Table 6. Recovery of PCBs at a level of 10 and $60 \mathrm{mg} \mathrm{kg}^{-1}$ with and without clean up $(n=5)$

\begin{tabular}{|c|c|c|c|}
\hline \multirow[t]{3}{*}{ Aroclor } & \multicolumn{3}{|c|}{ Recovery $(\%) \pm \operatorname{RSD}(\mathrm{n}=6)$} \\
\hline & \multicolumn{2}{|c|}{ Without clean up } & \multirow{2}{*}{$\begin{array}{c}\text { With clean up } \\
60 \mathrm{mg} \mathrm{kg}^{-1}\end{array}$} \\
\hline & $10 \mathrm{mg} \mathrm{kg}^{-1}$ & $60 \mathrm{mg} \mathrm{kg}^{-1}$ & \\
\hline 1242 & $<10$ & $45.3 \pm 4.4$ & $93.0 \pm 4.3$ \\
\hline 1254 & $82.4 \pm 2.0$ & $81.0 \pm 2.3$ & $93.5 \pm 2.1$ \\
\hline 1260 & $101.2 \pm 2.0$ & $96.0 \pm 2.1$ & $97.1 \pm 2.4$ \\
\hline
\end{tabular}

these compounds with the applied method is quantitative (> 80\%) for the heaviest PCBs, i.e., with a greater quantity of chlorine in the molecule. Nevertheless, the proposed method is not quantitative for low-molecularweight PCBs (Aroclor 1242) because of the interference produced by the coextracted mineral oil on the analyte signals in the retention time ranges corresponding to Aroclor 1242. However, as can be seen in Table 6, recovery is effective as a screening method in verifying oils contaminated with these compounds $\left(>50 \mathrm{mg} \mathrm{kg}^{-1}\right)$. For satisfactory recovery or lighter congeners, i.e., dichloro-, trichloro- and tretrachloro- (most abundant congeners in Aroclor 1242) a simple clean-up process was applied by using $n$-hexane as a solvent and sulphuric acid to clean up the extracted oil sample. ${ }^{11}$ Recoveries with and without clean up are shown in Table 6. A great increase in recovery is observed for the congeners that were previously interfered by oil (Aroclor 1242). The higher-molecular weight congeners kept their high recovery rate (Aroclor 1254 and 1260).

\section{Application of the methods to real samples}

The developed method was applied to 4 real contaminated transformer oil samples. Levels found were above those allowed, that is, above $50 \mathrm{mg} \mathrm{kg}^{-1}$, some of them being above 3 to $15 \mathrm{~g} \mathrm{~kg}^{-1}$.

Most of all the real samples contained Aroclor 1260, and, to a lesser extent, Aroclor 1254, thus it was not necessary to subject the samples to clean-up.

\section{Conclusions}

A screening method based on liquid-liquid extraction followed by GC-MS determination has been developed to determine PCBs in transformer oils. Results given by the method indicate that direct application of the proposed methodology at a 50-100 mg kg-1 concentration level, recoveries were quantitative for Aroclors 1254 and 1260, but they were low for Aroclor 1242, on account of interferences of traces of oil dissolved in methanol during the extraction process. Thus, for quantitative determination of the lighter congeners (Aroclor 1242), it was necessary to clean up the extract prior to its injection into GC-MS. Consequently, the developed methodology may be directly utilized (as screening) in order to determine whether or not (binary response $=$ yes $/$ no) there are PCBs in an oil sample, at a concentration level near the standard $(50 \mathrm{mg}$ $\mathrm{kg}^{-1}$ ). Otherwise in the case of extremely high or low concentrations, direct methodology would allow to discard more specific assays. 
If additional determination of the exact concentration of all the PCBs were desired, the sample would need cleanup with concentrated $\mathrm{H}_{2} \mathrm{SO}_{4}$, only in the case of a prevailing presence of di-, tri- and tretrachlorobiphenyls in Aroclor 1242.

\section{Acknowledgment}

The authors thank FONDECYT (Project 1030005) for financial support.

\section{References}

1. US-EPA, Method 4020, Screening for Polychlorinated Biphenyls by Immunoassay, 1996. http://www.epa.gov/ epaoswer/hazwaste/test/pdfs/4020.pdf access date, August 28, 2006.

2. US-EPA, Method 9079, Screening Test Method for Polychlorinated Biphenyls in Transformer Oil, 1996. http:// www.epa.gov/epaoswer/hazwaste/test/pdfs/9079.pdf access date May 17, 2006.
3. U.S-EPA, Method 8082, Polychlorinated Biphenyls (PCBs) by Gas Chromatography, 1996. http://www.epa.gov/epaoswer/ hazwaste/test/pdfs/8082.pdf

4. Ramil, M.; Rodriguez, I.; Cela, R.; J. Chromatogr., A. 2004, 1056, 263.

5. Gordon, R.; Szita, J.; Faeder, E.; Anal. Chem. 1982, 54, 478.

6. Schulz, D.; Petrick, G.; Duinker, J.; Environ. Sci. Technol. 1989, 23, 1396.

7. Kyoung, S.; Kim, H.; Chung, D.; Sim, K.; Kyoung, J.; Hee, Y.; Chung, R.; Organohalogen Compd. 2004, 66, 358.

8. Buthe, A.; Denker, E.; Chemosphere 1995, 30, 753.

9. Takada, M.; Toda, H.; Uchida, R.; Chemosphere 2001, 43, 455.

10. Takasuga, T.; Senthilkumar, K.; Matsumura, T.; Shiozaki, K.; Sakai, S-I.; Chemosphere 2006, 62, 469.

11. ASTM D4059, Standard Test Method for Analysis of Polychlorinated Biphenyls in Insulating Liquids by Gas Chromatography, West Conshohocken, PA 19428-2959 USA, 2005.

12. Luan, T.; Li, G.; Zhang, Z.; Anal. Chim. Acta 2000, 424,19.

Received: September 27, 2006 Web Release Date: July 30, 2007 